\title{
Pathway Analysis Hints Towards Beneficial Effects of Long-Term Vibration on Human Chondrocytes
}

\author{
Ronald Lützenberg ${ }^{\mathrm{a}} \quad$ Kendrick Solano ${ }^{\mathrm{a}} \quad$ Christoph Buken $^{\mathrm{a}} \quad$ Jayashree Sahana ${ }^{\mathrm{b}}$ \\ Stefan Riwaldt ${ }^{\mathrm{b}}$ Sascha Kopp ${ }^{\mathrm{a}}$ Marcus Krüger ${ }^{\mathrm{a}}$ Herbert Schulz ${ }^{\mathrm{c}}$ Kathrin Saard \\ Norbert Huebner ${ }^{d}$ Ruth Hemmersbache Johann Bauer ${ }^{\mathrm{f}} \quad$ Manfred Infanger $^{\mathrm{a}}$ \\ Daniela Grimm a,b,g Markus Wehland ${ }^{a}$
}

${ }^{a}$ Clinic for Plastic, Aesthetic and Hand Surgery, Otto-von-Guericke-University Magdeburg, Magdeburg, Germany, ${ }^{b}$ Department of Biomedicine, Aarhus University, Aarhus C, Denmark, 'Cologne Center for Genomics, University of Cologne, Cologne, dMax-Delbrück-Center for Molecular Medicine, Berlin, eDLR, German Aerospace Centre, Institute of Aerospace Medicine, Gravitational Biology, Cologne, ${ }^{f} \mathrm{Max}-$ Planck-Institute of Biochemistry, Martinsried, ${ }^{9}$ Gravitational Biology and Translational Regenerative Medicine, Faculty of Medicine and Mechanical Engineering, Otto-von-Guericke-University-Magdeburg, Magdeburg, Germany

\section{Key Words}

Chondrocytes • Vibration - Cytoskeleton - Extracellular matrix proteins • Gene expression • Pathway analysis

\footnotetext{
Abstract

Background/Aims: Spaceflight negatively influences the function of cartilage tissue in vivo. In vitro human chondrocytes exhibit an altered gene expression of inflammation markers after a two-hour exposure to vibration. Little is known about the impact of long-term vibration on chondrocytes. Methods: Human cartilage cells were exposed for up to $24 \mathrm{~h}$ (VIB) on a specialised vibration platform (Vibraplex) simulating the vibration profile which occurs during parabolic flights and compared to static control conditions (CON). Afterwards, they were investigated by phase-contrast microscopy, rhodamine phalloidin staining, microarray analysis, qPCR and western blot analysis. Results: Morphological investigations revealed no changes between CON and VIB chondrocytes. F-Actin staining showed no alterations of the cytoskeleton in VIB compared with CON cells. DAPI and TUNEL staining did not identify apoptotic cells. ICAM-1 was elevated and vimentin, beta-tubulin and osteopontin proteins were significantly reduced in VIB compared to CON cells. qPCR of cytoskeletal genes, ITGB1, SOX3, SOX5, SOX9 did not reveal differential regulations. Microarray analysis detected 13 differentially expressed genes, mostly indicating unspecific stimulations. Pathway analyses demonstrated interactions of PSMD4 and CNOT7 with ICAM. Conclusions: Long-term vibration did not damage human chondrocytes in vitro. The reduction of osteopontin protein and the down-regulation of PSMD4 and TBX15 gene expression suggest that in vitro long-term vibration might even positively influence cultured chondrocytes.

D. Grimm and M. Wehland contributed equally to this work. 


\section{Introduction}

Chondrocytes or cartilage cells are the only cell type detectable in articular cartilage. In healthy cartilage, they produce and are embedded in a stable but elastic extracellular matrix (ECM) [1]. This ECM composition with collagens and proteoglycans provides resistance against mechanical forces and friction for the joints and determines the overall properties and functionality of the cartilage [2]. Articular cartilage is important for joint mobility and serves as a mechanical, frictionless cushion during movement [3].

Whole-body vibration (WBV) has been used to treat musculoskeletal diseases like osteoarthritis (OA), but the direct effect of vibration on joint cartilage is not clear. A recent study showed that WBV induced cartilage degeneration in mice [4]. Higher frequencies of WBV ( $30 \mathrm{~Hz}$ and $40 \mathrm{~Hz}$ ) in a rabbit model had a negative influence on cartilage volume and cartilage resorption, whereas lower frequencies $(10 \mathrm{~Hz}$ and $20 \mathrm{~Hz})$ decreased cartilage resorption, accelerated cartilage formation, and delayed cartilage degradation especially at the $20 \mathrm{~Hz}$ regimen [5].

Little is known about the direct impact of vibration on chondrocytes in vitro. It has been demonstrated that mechanical vibrations can elevate the proliferation of chondrocytes in monolayer cultures [6]. These vibration effects seem to be limited to the early stages where ECM (collagen and proteoglycans) accumulation is at a minimum [6].

A prolonged stay in orbit affects the health of humans in space. Bone loss and cartilage breakdown in microgravity occurs after a long-term spaceflight [7]. Due to the poor regenerative capacity of cartilage tissue, this degradation may disturb the flight crews' mobility and may negatively influence mission activities [8]. Certainly, microgravity is a key factor for these degradation processes, but also other factors such as cosmic radiation and vibration might be important to alter cartilage tissue.

To receive more information about the time point when these changes on the cellular level occur, chondrocytes were investigated during short-term microgravity obtained during a parabolic flight (PF) [9]. As a control, a corresponding short-term, two-hour period of vibration as it occurs during the PF was affecting cartilage cells (upregulated inflammatory IL6 and CXCIL8 mRNAs, downregulated growth factor genes like EGF, VEGF, FGF17) [9]. However, no significant changes in morphology and gene expression levels of cytoskeletal genes, cell adhesion molecules, integrins, as well as of TGFB, CAV1 and SOX9 were observed during vibration [10].

To our knowledge no information exists concerning the impact of long-term vibration on chondrocytes in vitro. Therefore, these experiments are designed to determine the influence of a 24-hour vibration-exposure of human chondrocytes on gene expression and protein content of selected factors important for various biological processes like cytoskeleton, ECM, cell adhesion, apoptosis, growth and others. Vibrations may influence the cells and the human body during the launch of a rocket, during the flight of a plane in parabolic campaigns vibration $[11,12]$ or during normal passenger flights. Therefore, it is important to increase our knowledge in this field and to investigate whether long-term vibration has a detrimental or even beneficial effect for chondrocyte growth in vitro. Moreover, the results of this study are of high importance for regenerative medicine and orthopedics.

\section{Materials and Methods}

\section{Cells and culture medium}

Human chondrocytes derived from hip joint cartilage were purchased from Provitro (Berlin, Germany). They were cultured in Chondrocyte Growth Medium (CGM; Provitro®, Berlin, Germany) supplemented with $10 \%$ fetal calf serum (Provitro®, Berlin, Germany) and antibiotics - $100 \mathrm{IU}$ penicillin/mL and 100 $\mu \mathrm{g}$ streptomycin/mL (Provitro®, Berlin, Germany). The cells from frozen stocks (passage 1) were grown in T175 cell culture flasks ( $175 \mathrm{~cm}^{2}$; Sarstedt, Nümbrecht, Germany) until sub-confluent layers were obtained. Afterwards, the cells were split (passage 2) in 5 T175 cell culture flasks and after reaching confluence 4 


\section{Cellular Physiology Cell Physiol Biochem 2018;47:1729-1741 \begin{tabular}{l|l|} 
and Biochemistry Published online: June 28, 2018 & $\begin{array}{l}\text { C } 2018 \text { The Author(s). Published by S. Karger AG, Basel } \\
\text { www.karger.com/cpb }\end{array}$ \\
\hline
\end{tabular}}

Lützenberg et al.: Chondrocytes and Vibration

T175 were split (passage 3) in 80 T25 cell culture flasks (25 $\mathrm{cm}^{2}$; Sarstedt, Nümbrecht, Germany) for the vibration experiments ( $\mathrm{n}=40$ for vibrated samples and $\mathrm{n}=40$ as $1 \mathrm{~g}$-control samples).

For histological investigations, the chondrocytes were seeded in slide flasks one day before the experiments ( $n=40$ each group; Thermo Fisher Scientific, Waltham, MA, USA).

\section{Vibration experiments}

The Vibraplex vibration platform (frequency range $0.2 \mathrm{~Hz}-14 \mathrm{kHz}$ ) was used to create vibrations like to the ones occurring during parabolic plane flights. The device is driven by an amplified wave signal. The injected wave signal is equal to a $1 / \mathrm{f}^{2}$ noise (red noise). The signal was generated with the software WaveLab 4.0 from Steinberg. The device was described in detail in [10].

\section{F-actin staining}

F-actin was visualized by means of rhodamine-phalloidin staining (Molecular Probes) [10]. For this purpose, seeded cells were fixed for 30 min with 4\% PFA (in DPBS), washed twice with DPBS, incubated with $5 \mathrm{mg} / \mathrm{mL}$ fluorescent phalloidin-conjugate solution in DPBS with 1\% bovine serum albumin for 20 min at room temperature, and then washed 3 times with DPBS to remove unbound phalloidin conjugate. Afterwards, the nuclei were stained with Hoechst 33342 (Molecular Probes) for 5 min and washed twice with DPBS. For evaluation, the samples were mounted with Vectashield (Vector Laboratories) and analyzed microscopically.

\section{Hematoxylin-eosin and Elastica-van-Gieson staining}

Hematoxylin-eosin- and Elastica-van-Gieson-staining procedures were used to evaluate the cell morphology of the chondrocytes. The methods were published earlier [13-15]. All samples were visualized by light microscopy. The samples were investigated by microscopy using a LEICA DM2000 microscope equipped with a Leica DFC310 FX digital CCD color camera.

\section{Microscopy}

F-actin stained cells were analyzed with a Leica TCS SP8 confocal laser scanning microscope (Leica Microsystems, Wetzlar, Germany).), equipped with a Plan-Apochromat 3631.4 objective. Excitation and emission wavelengths were $\lambda_{\text {exc }}=488 \mathrm{~nm}$ and $\lambda_{\mathrm{em}}=505 \mathrm{~nm}$ for FITC. All samples were analyzed with the help of the image analysis program Scion Image (Version 1.63 MacOs; Scion Corporation, Frederick, MD, USA). Phase contrast microscopy was done with a LEICA DM2000 microscope equipped with a Leica DFC310 FX digital CCD color camera.

\section{Viability staining}

TdT-mediated dUTP-biotin nick end labeling (TUNEL) staining was done according to the manual provided by the manufacturer (Calbiochem ${ }^{\circledR}$, FragEL ${ }^{\mathrm{TM}}$ DNA Fragmentation Detection Kit, Fluorescent - TdT Enzyme). Cells for 4',6-diamidino-2-phenylindole (DAPI) staining were fixed with 3.7\% formaldehyde (room temperature, $10 \mathrm{~min}$ ) and incubated in $1 \mu \mathrm{g} / \mathrm{mL}$ DAPI in PBS for $15 \mathrm{~min}$ (Invitrogen/Molecular Probes, Darmstadt, Germany). Stained cell samples (VIB and static CON) were investigated utilizing a Leica DM 2000 microscope connected to an external light source, Leica EL 6000 (Leica Microsystems GmbH, Wetzlar, Germany). Palatine tonsil cross-sections were taken as positive control using an objective with a calibrated magnification of 400x.

\section{Western blot analyses}

Western blotting, immunoblotting, and densitometry were performed employing standard protocols $[14,15]$. We used the Biorad ChemiDoc XRT+ device. The number of investigated samples/per group was $\mathrm{n}=4$.

Equal amounts of $20 \mu \mathrm{L}$ lysate, containing $3 \mu \mathrm{g} / \mu \mathrm{L}$ protein, were loaded onto precast TGX stain-free gels (Bio-Rad, Munich, Germany). Each western blot was performed 3 times. Anti-beta-tubulin, and antivimentin, were used at a dilution of 1:1000 (Cell Signaling Technology, Inc.); anti-osteopontin antibody was used at a dilution of 1:1000 (Rockland Immunochemicals Inc., Limerick, PA, USA) as well as the anti-integrin-beta1 antibody (Epitomics, Burlingame, CA, USA). The anti-SOX9 antibody was applied at a dilution of 1:500 (Life Technologies). In addition, we used an anti-caveolin-1 antibody (1:1000; Abcam). 
Lützenberg et al.: Chondrocytes and Vibration

The anti-ICAM-1 antibody was purchased from Santa-Cruz Biotechnologies (Heidelberg, Germany) and diluted 1: 500. The secondary horseradish peroxidase-linked antibody was used at a dilution of 1:4000 (Cell Signaling Technology, Inc.).

Ponceau $\mathrm{S}$ red staining was used as an alternative to housekeeping proteins as loading controls. The membranes were analyzed using ImageJ software (U.S. National Institutes of Health, Bethesda, MD, USA; http://rsb.info.nih.gov/ij/), for densitometric quantification of the bands. Ponceau $S$ was evaluated according to standard protocols.

\section{RNA isolation and quantitative real-time PCR ( $q P C R$ )}

RNA isolation was performed using the RNeasy Mini Kit (Qiagen, Hilden, Germany), with an additional DNase digestion step (Qiagen) in order to eliminate residual DNA contaminations. Subsequently, the amount of RNA was quantified via a Photometer Ultrospec2010 (Amersham Biosciences, Freiburg, Germany). The first strand cDNA synthesis kit (Thermo Fisher Scientific, Waltham, US) was used for reverse transcription. qPCR was performed using the 7500 Fast Real-Time PCR System (Applied Biosystems, Darmstadt, Germany) according to routine protocols [16, 17]. cDNA-selective-primers were synthesized by TIB Molbiol (Berlin, Germany) and are listed in Table 1. The primers were designed using Primer Express (Applied Biosystems, Darmstadt, Germany) to have a $\mathrm{T}_{\mathrm{m}}$ of $\sim 60^{\circ} \mathrm{C}$ and to span exonexon boundaries. All samples were measured in triplicate. For normalization, 18S rRNA was used as a housekeeping gene. The comparative $C_{T}\left(\Delta \Delta C_{T}\right)$ method was used for relative quantification of transcription levels and $1 g$ was defined as $100 \%$ for reference.

Whole genome microarray analysis

The Illumina HumanHT-12 v4 Expression BeadChip arrays have been normalized using the GenomeStudio V2011.1. with Gene Expression Module 1.9.0. and quantile normalization without background correction. For each group (control and vibration), six independent microarrays were analyzed. After quantile normalization and exclusion of low or not expressed genes (minimum Illumina detection p-value > 0.05) differences between chondrocyte control, and vibrated chondrocytes was analyzed using Student's t-test. None of the probes reached a 5\% FDR level [18].

Differentiation of the expression profiles was performed using hierarchical clustering over 13 probes with a nominal p-value $<0.001$. The cluster analysis was done using Partek Genomic Suite 6.6 applying hierarchical average linkage clustering on standardized log2 signal values.

\section{Pathway analyses}

To investigate the mutual regulation of genes and to visualize localization and interactions between proteins, we entered relevant UniProtKB entry numbers in the Pathway Studio v.11 software (Elsevier Research Solutions, Amsterdam, The Netherlands). Graphs were generated for gene expression and protein regulation and binding. The method was described previously [19, 20].

\section{Statistical analysis}

All statistical analyses were performed using SPSS 16.0 software (SPSS, Inc., Chicago, IL, USA). We used the Mann-Whitney-U-test to assess differences, which were considered significant at the level of $\mathrm{p}<0.05$. All data are presented as means \pm standard deviation.
Table 1. Primers used for quantitative real-time PCR. All sequences are given in 5' to 3' direction

\begin{tabular}{|c|c|c|}
\hline Gene & Primer Name & Sequence \\
\hline \multirow{2}{*}{$18 S$ rRNA } & $18 \mathrm{~S}-\mathrm{F}$ & GGAGCCTGCGGCTTAATTT \\
\hline & $18 \mathrm{~S}-\mathrm{R}$ & CAACTAAGAACGGCCATGCA \\
\hline \multirow{2}{*}{ АCTA2 } & ACTA2-F & GAGCGTGGCTATTCCTTCGT \\
\hline & ACTA2-R & TTCAAAGTCCAGAGCTACATAACACAGT \\
\hline \multirow{2}{*}{ ACTB } & ACTB-F & TGCCGACAGGATGCAGAAG \\
\hline & ACTB-R & GCCGATCCACACGGCGTACT \\
\hline \multirow{2}{*}{$B M P 2$} & BMP2-F & GACCTGTATCGCAGGCACTCA \\
\hline & BMP2-R & TCGTTTCTGGTAGTTCTTCCAAAGA \\
\hline \multirow[b]{2}{*}{ CAV1 } & CAV1-F & GTACGACGCGCACACCAA \\
\hline & CAV1-R & TCCCTTCTGGTTCTGCAATCA \\
\hline \multirow[b]{2}{*}{ ICAM1 } & ICAM1-F & CGGCTGACGTGTGCAGTAAT \\
\hline & ICAM1-R & CTTCTGAGACCTCTGGCTTCGT \\
\hline \multirow[b]{2}{*}{ INTA1O } & INTA10-F & CGAAGACTGGTAGGGAAACTGTTTA \\
\hline & INTA10-R & GCCGACTGAGGTTCTTTGCT \\
\hline \multirow[b]{2}{*}{ INTB1 } & INTB1-F & GAAAACAGCGCATATCTGGAAATT \\
\hline & INTB1-R & CAGCCAATCAGTGATCCACAA \\
\hline \multirow[b]{2}{*}{ KRT8 } & KRT8-F & GATCTCTGAGATGAACCGGAACA \\
\hline & KRT8-R & GCTCGGCATCTGCAATGG \\
\hline \multirow[b]{2}{*}{ SOX5 } & SOX5-F & GGTGGCTGCTGTGACAAAGGGA \\
\hline & SOX5-R & ACGGAGAGGCTGGTCGCTTG \\
\hline \multirow[b]{2}{*}{ SOX6 } & SoX6-F & GCAGTGATCAACATGTGGCCT \\
\hline & SOX6-R & CGCTGTCCCAGTCAGCATCT \\
\hline \multirow{2}{*}{$\operatorname{sox} 9$} & SOX9-F & TTGAGACCTTCGACGTCAATGAG \\
\hline & SOX9-R & TCTGGCCACGAGTGGCC \\
\hline \multirow{2}{*}{ SPP1 } & SPP1-F & CGAGGTGATAGTGTGGTTTATGGA \\
\hline & SPP1-R & CGTCTGTAGCATCAGGGTACTG \\
\hline \multirow[b]{2}{*}{ TGFB1 } & TGFB1-F & CACCCGCGTGCTAATGGT \\
\hline & TGFB 1-R & AGAGCAACACGGGTTCAGGTA \\
\hline \multirow[b]{2}{*}{ TUB } & TUBB-F & CTGGACCGCATCTCTGTGTACTAC \\
\hline & TUBB-R & GACCTGAGCGAACAGAGTCCAT \\
\hline \multirow{2}{*}{ VIM } & VIM-F & TTCAGAGAGAGGAAGCCGAAAAC \\
\hline & VIM-R & AGATTCCACTTTGCGTTCAAGGT \\
\hline
\end{tabular}




\section{Cellular Physiology Cell Physiol Biochem 2018;47:1729-1741 \begin{tabular}{c|c|c|} 
DOI: 10.1159/000491006 & O 2018 The Author(s). Published by S. Karger AG, Basel \\
www.karger.com/cpb
\end{tabular} Lützenberg et al.: Chondrocytes and Vibration}

\section{Results}

\section{Phase contrast microscopy}

After $24 \mathrm{~h}$ of vibration, no morphological differences between static control cells (Fig. 1A) and vibrated chondrocytes (Fig. 1B) were visible. Both samples showed regular cell morphologies without any detectable aberration.

\section{Rhodamine-phalloidin staining}

Both static control (Fig. 1C) as well as vibrated cells (Fig. 1D) displayed a normal distribution and structure of actin fibers with no signs of damage, no disarrangements or deposits of F-actin at the cellular membranes.

\section{Further histological analyses}

To characterize the cell morphology of both control as well as vibrated chondrocytes, we additionally performed hematoxylin and eosin (HE) as well as Elastica van Gieson (EVG) staining. HE staining revealed no signs of necrosis, but normal morphology in both groups. Furthermore, proliferation rates did not differ. Collagen and elastin fibers content as well as distribution were similar in both control and vibrated cells, as demonstrated by EVG staining.

\section{DAPI and TUNEL staining for the detection of apoptosis}

Cells subjected to vibration as well as static control cells were analyzed with DAPI and TUNEL staining to assess the extent of apoptosis. Cross-sections of palatine tonsils were used as positive control. No apoptotic cells could be detected in both vibrated and control samples (Fig. 1 E-H).

Western blot analysis of proteins involved in the cytoskeleton, cell-cell contact and cell adhesion

We selected proteins of interest which are involved in several crucial biological processes such as the organization of the cytoskeleton, cell adhesion or cellcell-contact in order to investigate the influence of vibration on the stability and integrity of the single cells as well of the whole cell layer.

No changes in the protein content between control and vibrated cells were detected for integrin $\beta-1$ (ITGB1, Fig. 2A), SOX-9 (SOX9, Fig. 2B), caveolin-1 (CAV1, Fig. 2C), intercellular adhesion molecule 1 (ICAM1, Fig. 2F) and intact osteopontin (OPN, Fig. 2G).

The proteins vimentin (VIM, Fig. 2D), beta- 1 tubulin (TUBB, Fig. 2E), and the MMP-cleavage derived $32 \mathrm{kDa}$ fragment of osteopontin (OPN, Fig. $2 \mathrm{H}$ ), on the other hand, were significantly reduced under vibration.

Quantitative real-time PCR (qPCR) of selected gravitationally sensitive candidate genes

In order to further characterize the influence of vibration on cultured chondrocytes, we examined the gene expression of genes found to be differentially regulated in chondrocytes subjected to simulated or real microgravity. In summary, vibration did not have

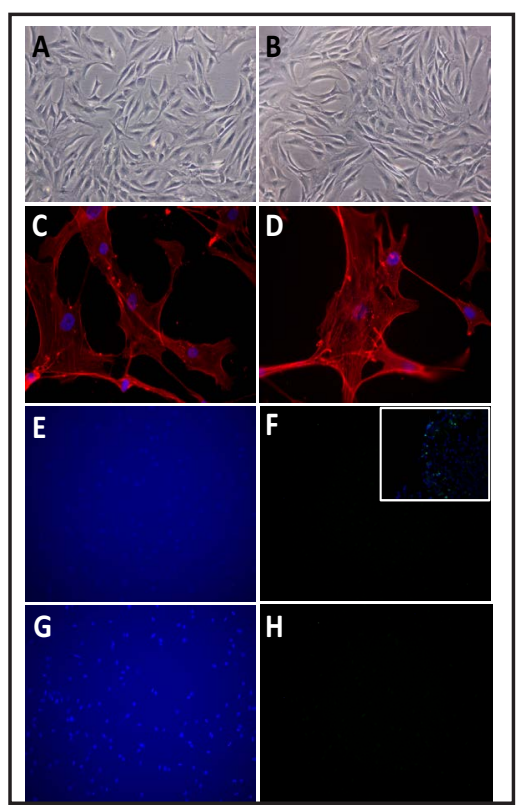

Fig. 1. Morphological and viability assessment. Chondrocytes exposed to the Vibraplex device were analyzed by phase contrast microscopy (B) and F-actin staining (D), and compared to their corresponding static controls (A, $\mathrm{C}$, respectively). No differences were found between the two groups. DAPI and TUNEL staining was performed to detect dead or apoptotic cells. No apoptotic cells were found. (E) DAPI static controls; (F) TUNEL static controls; (G) DAPI $24 \mathrm{~h}$ vibration; (H) TUNEL $24 \mathrm{~h}$ vibration; (F) insert human tonsilla palatina positive control. 
an impact on the expression of our chosen set of genes comprising ACTA2, ACTB, BMP2, CAV1, ICAM1, INTA10, INTB1, KRT8, SOX5, SOX6, SOX9, SPP1, TGFB1, TUBB, and VIM (Fig. 3 A-O).

\section{Whole genome} microarray analysis

From the total of 28855 detected probes, only 13 were found to be differentially expressed $(\mathrm{p}<0.001)$ between control and vibrated samples CNOT7, COMMD2, RPS26L, BAIAP2, HNRPUL1, Hs.445274, and LOC653157 were downregulated in vibrated chondrocytes, while TBX15, LOC641365, CYBASC3, PSMD4, GPR112, and $A C O 2$ were upregulated

Fig. 3. qPCR analysis of previously identified gravisensitive genes. (A) ACTA2; (B) ACTB; (C) BMP2,

(D) CAV1, (E) ICAM1, (F) INTA10, (G) INTB1, (H) KRT8, (I) SOX5, (J) SOX6, (K) SOX9, (L) SPP1, (M) TGFB1, (N) TUBB, and (O) VIM.
Fig. 2. Protein content analyzed by western blot technique. (A) ITGB1; (B) SOX9; (C) CAV1; (D) VIM; (E) TUBB; (F) ICAM1; (G) OPN $66 \mathrm{kD}$ and $(\mathrm{H})$ OPN $32 \mathrm{kD} . *$ indicate significant differences at $\mathrm{p}<0.05$.

,

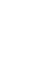


Fig. 4. Differentially expressed genes detected by whole genome microarray analysis (A, B) and expanded interaction analysis of genes detected by microarray analysis and gravisensitive genes investigated by qPCR (C, D). (A) Heatmap of the 13 differentially expressed genes. Red: higher expression; blue: lower expression. (B) STRING analysis of the 13 differentially expressed genes. No interaction on gene or protein level were found. Balls represent the single genes, with 3D structure included, if known. Possible interactions would be represented by lines connecting two or more genes. (C) Mutual regulation network at gene expression level. (D) Mutual regulation network at protein level and cellular localization of identified proteins.

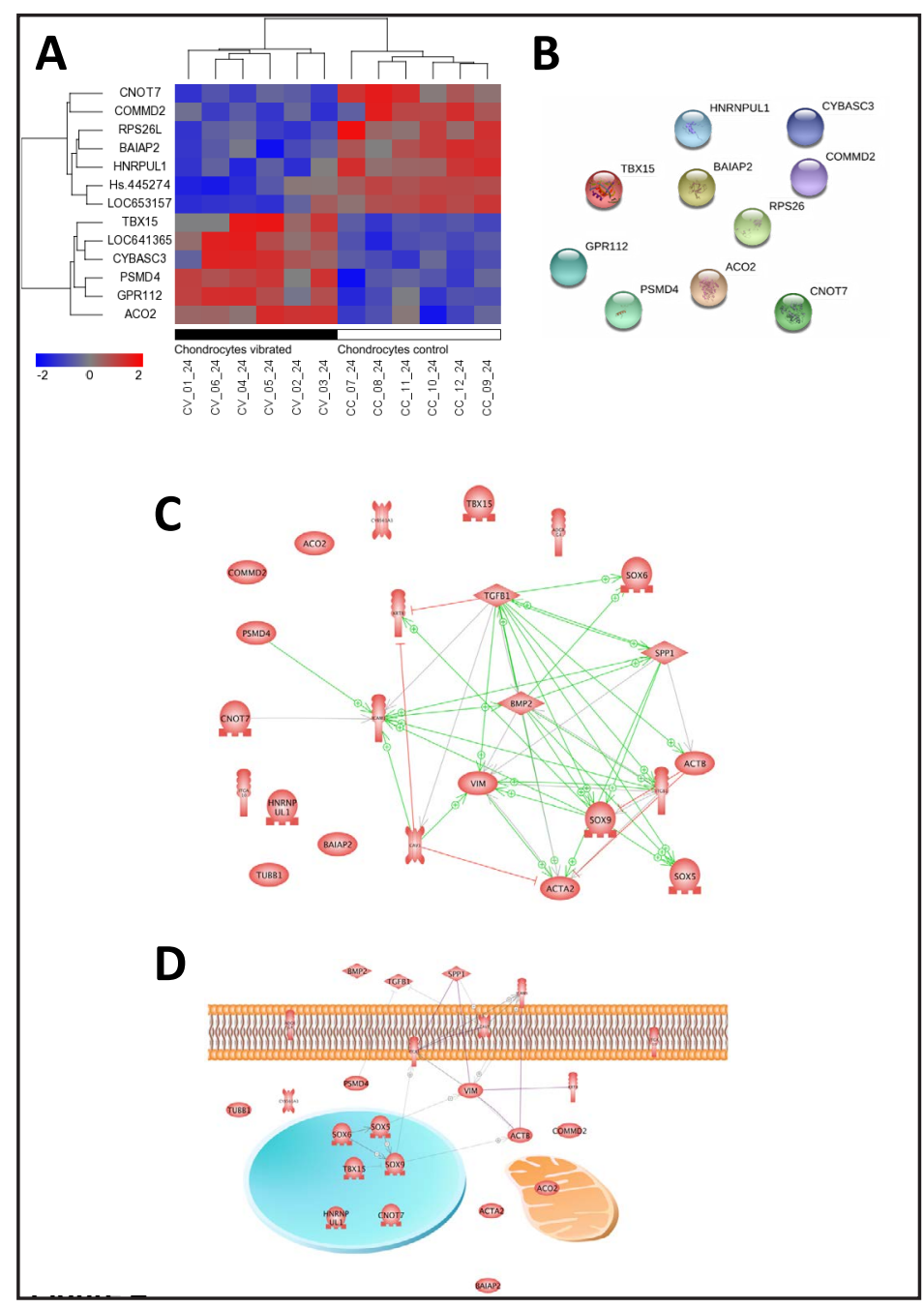

in vibrated chondrocytes in comparison to control samples (Fig. 4A). A short-annotated overview of the regulated genes is given in Table 2. A further STRING analysis [21] (Version 10.5, using confidence levels of both 0.4 and 0.15 , available from https://string-db.org) revealed, that the regulated genes do not interact with one another and do not share a common pathway in which they are involved (Fig 4B).

However, a part of the genes and their products (CNOT7, PSMD4, TBX15) recognized by microarray technology had an influence on expression and function of the proteins selected for the western blot analysis (Fig. 2) which show strong interaction activity at gene (Fig. 4C) and gene product levels (Fig. 4D). On the gene level the nuclear protein CNOT7 is able to regulate ICAM1 and CXCIL8 expression (Fig. 4C, [22]). It is known that CNOT7 silencing stabilized ICAM1 and CXCIL8 mRNAs and increased ICAM-1 and IL-8 production following TNF- $\alpha$ stimulation [23]. It is of special interest as osteopontin, a factor that up-regulates ICAM-1 (Fig. 4C, [24]) is totally abolished after vibration. Moreover, VIM which is often stabilized by OPN [25] is significantly reduced. This fact could contribute to enhanced stability of ICAM-1 [26].

\section{Discussion}

Chondrocytes are the major cells distributed in the dense ECM of articular cartilage. They exhibit a well-differentiated phenotype with unique physiological functions determining 
Table 2. Overview of the differentially expressed genes detected by whole genome microarray analysis

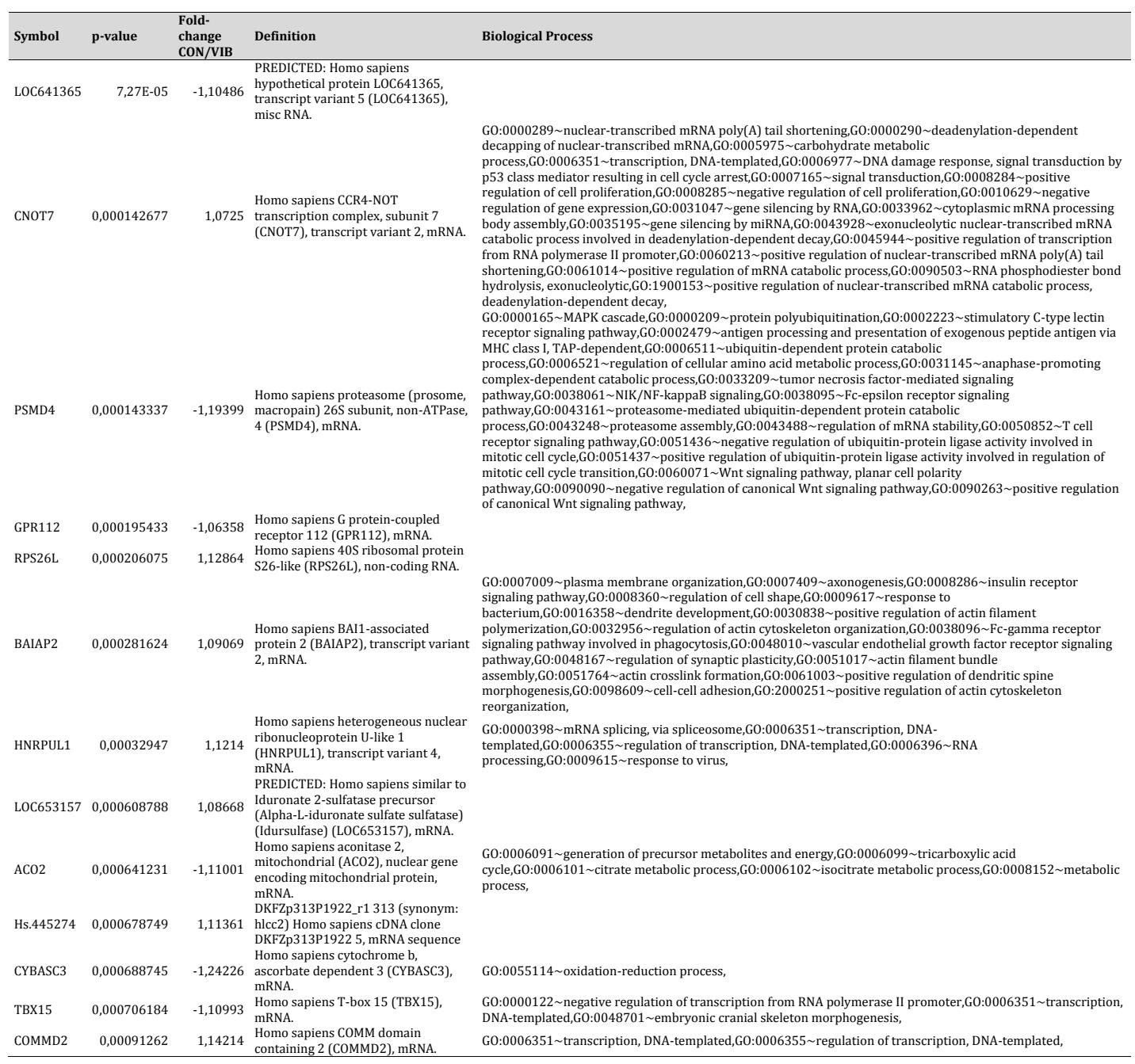

the properties of the load-bearing cartilage tissue. Diseases of the cartilage comprise OA which increased in prevalence across the world due to the aging population and it is one of the most frequent causes of chronic pain. Because there is no causal treatment of OA, the major objective of physicians is to use current available therapies and to slow down the progression of this disease. Therefore, new research focusing on the chondrocytes is necessary. A recent study determined the effects of low-magnitude whole WBV on cartilage degradation, bone/cartilage turnover, and OA joint function in a rabbit knee OA model [27]. The authors reported that lower frequency $(20 \mathrm{~Hz})$ WBV can improve bone microstructure, increase bone turnover, delay cartilage degeneration and improve limb function in this rabbit OA model [27]. Little is known about vibration effects on the cellular level.

In this study, we investigated the long-term $(24 \mathrm{~h})$ effect of vibrations on human chondrocytes in vitro. It is known that mechanical vibrations increase the proliferation of articular chondrocytes in high-density cultures of isolated bovine articular chondrocytes [6]. In addition, vibration promoted differentiation of rat pheochromocytoma (PC12) cells, which supported the hypothesis that effects of the physical environment can influence cellular differentiation [28].

Chondrocytes embedded in the ECM of the cartilage are known to be responsive to mechanical forces such as pressure, shear stress or vibrations [29-34]. During OA progression, the ECM is actively remodeled by chondrocytes under inflammatory conditions [35]. These alterations affect the biomechanical environment of chondrocytes, which leads 


\section{Cellular Physiology Cell Physiol Biochem 2018;47:1729-1741 \begin{tabular}{c|c} 
DOI: 10.1159/000491006 & O 2018 The Author(s). Published by S. Karger AG, Basel \\
www.karger.com/cpb
\end{tabular} \\ Lützenberg et al.: Chondrocytes and Vibration}

to disease progression. ECM remodeling in $\mathrm{OA}$ progression also influences the contribution of mesenchymal stem cells in the repair process by inhibiting their chondrogenic differentiation [35].

In fact, it has been proposed that mechanical stress may be a useful tool for tissue engineering of articular cartilage [36]. Here, we focused on vibrations, as we have already conducted short-term studies on chondrocytes earlier $[9,10]$, which hinted towards a negative influence of vibration on cultured chondrocytes after $2 \mathrm{~h}$.

We have prolonged the vibration time up to $24 \mathrm{~h}$ and in contrast to our earlier findings, we did not see a negative effect on chondrocytes in vitro. It is interesting to note, that none of the pro-inflammatory genes (such as IL6 and CXCIL8) which were differentially regulated after $2 \mathrm{~h}$ of vibration were detected as differentially expressed after $24 \mathrm{~h}$ employing a whole genome microarray analysis. Moreover, none of the previously identified microgravitysensitive genes [10] were found to be regulated in a separate qPCR analysis. An overview of the candidate proteins analyzed by Western blot, qPCR, and whole genome microarray is given in Table 3. These results indicate that the chondrocytes adapt to vibration with time, which is an interesting finding, especially with regard to long-distance flights.

Only 13 genes have been identified to be differentially expressed after $24 \mathrm{~h}$. The most interesting one was BAIAP2 (BAI1 associated protein 2, also known as IRSp53). The corresponding protein constitutes an insulin receptor substrate [37], and it has been shown that it is involved in the regulation of lamellipodia formation via activation of the WAVE2 protein [38]. Of note, it has recently been observed, that the formation of filopodia and lamellipodia in thyroid cancer cells were affected by the conditions of a TEXUS sounding rocket flight, which also includes vibration during the take-off phase [39]. Some of the identified genes listed in Table 2, if already characterized, were involved in unrelated general metabolic processes in the cell such as regulation of transcription, oxidation and reduction processes, generation of precursor metabolites and energy, mRNA splicing or DNA-templated transcription. This hints towards an unspecific activation of the vibrated cells as a general answer to the altered culture conditions, but offers no further insight into possible specific reactions of chondrocytes to long-term vibrations. Overall, these results seem to indicate that chondrocytes are able to adapt to vibrational stress over time. While short-term vibrations clearly exhibited a detrimental effect on cultured chondrocytes, our current study shows that the cells are obviously able to counteract these initial perturbations and revert to a normal state with only minor and more generalized reactions on the molecular level.

\section{Pathway analyses revealed interactions of ICAM with PSMD4 and CNOT7}

We found a downregulated T box transcription factor TBX15 in vibrated chondrocytes. High amounts of this transcription factor were found in human aortic valve interstitial cells (hAVICs) compared to human mitral valve interstitial cells [40]. Sun et al. identified TBX15 as a potential calcification-preventing factor in hAVICs [40].

PSMD4, or $26 \mathrm{~S}$ proteasome non-ATPase regulatory subunit 4 , is differentially regulated and is interacting with ICAM-1 (Fig. 4). This protein is of interest because the proteasome and its subunits are of clinical significance. A dysfunction can be associated with the underlying pathophysiology of specific diseases. The ubiquitin proteasome complex is also involved in the regulation of inflammatory responses. This activity is usually attributed to the role of proteasomes in the activation of $\mathrm{NF}-\kappa \mathrm{B}$ which further regulates the expression of proinflammatory cytokines and cell adhesion molecules like ICAM-1 and others [41].

Another interaction was found for CNOT7 (CCR4-NOT transcription complex subunit 7) and ICAM1. The carbon catabolite repressor protein 4 (CCR4)-negative on TATA (NOT) 
complex includes multiple subunits and is detecTable in human cells [22]. CCR4-associated factor 1 (CAF1) is involved in the regulation of ICAM1 and CXCIL8 expression. This interesting interaction reveals that mechanical vibration might influence cell adhesion and survival of the chondrocytes. In human pulmonary microvascular endothelial cells CNOT7/hCAF1 are involved in ICAM-1 and IL-8 regulation by tristetraprolin [23].

\section{Impact of vibration on osteopontin}

An interesting finding was the reduced amount of osteopontin in the human chondrocytes after 24 hours, which indicates a cell-protective influence of long-term vibration on the human chondrocytes. Osteopontin is associated with the severity and progression of OA [42].

It is secreted by various cell types, including macrophages, lymphocytes, epithelial cells, vascular smooth muscle cells, and even chondrocytes as well as synoviocytes [4345]. Interestingly, mRNA expression and protein abundance of OPN are associated with the pathogenesis of OA [42]. Pullig et al. had demonstrated that the SPP1 mRNA isolated from human OA cartilage is elevated compared to normal cartilage samples [46]. Elevated OPN plasma levels in OA patients were found [47], indicated that SPP1 mRNA expression is associated with progression of OA. Therefore, we may conclude that the reduced osteopontin content in our experimental setting may indicate a beneficial effect of long-term vibration on chondrocytes.

Recent studies showed that phosphorylated osteopontin increases apoptosis and pro-inflammatory cytokine expression in human knee OA chondrocytes [48]. The authors concluded that inhibition of p-osteopontin may provide a novel effective strategy to slow or halt OA progression [48].

\section{Influence of vibration on the cytoskeleton}

The chondrocyte cytoskeleton consists of actin microfilaments, microtubules and vimentin [49]. On the protein level, vimentin was significantly downregulated under vibration. Vimentin belongs to the intermediate filaments [50] and as such is involved in the maintenance of cell shape, cytoplasm integrity, and stabilization of the cytoskeleton [51]. Furthermore, vimentin proved to be sensitive to exposure to culture conditions on a Random Positioning Machine (RPM), where after $4 \mathrm{~h}$ disruptions in the vimentin network occurred [52]. Similar effects have also been observed in samples subjected to 31 parabolas (about $2 \mathrm{~h}$, fixation after the $31^{\text {st }}$ parabola) during a parabolic flight [10]. However, after $16 \mathrm{~h}$ on the RPM, these disruptions were already partially repaired by the cell, which was accompanied by an increase of vimentin protein production [52]. This indicates, that obviously within a day, chondrocytes are able to adapt to different culture conditions with altered mechanical environments.

Vibration reduced beta-tubulin protein significantly supporting the thesis that the microtubule cytoskeleton is not adapting after $24 \mathrm{~h}$ and is still affected. Another study showed comparable data of follicular thyroid cancer cells (ML-1 cell line) exposed to a twohour period of vibration. The protein content of alpha-tubulin was significantly reduced in ML-1 cells after two hours [53].

Therefore, we speculate, that in this study we can see very late stages of the adaption process of chondrocytes to cultivation under vibration. If any changes occurred in the actin cytoskeleton, they have probably been repaired at the time of observation. The detected downregulation of vimentin could be the consequence of an earlier overproduction of the protein to reconstruct the possibly disrupted vimentin network.

\section{Conclusion}

In this study, we have shown that chondrocytes do not undergo any noteworthy morphological changes when cultured under conditions of vibrations on a Vibraplex device for $24 \mathrm{~h}$, simulating the vibration profile occurring during parabolic flight. Therefore, we conclude that vibrations in the frequency range of $0.2 \mathrm{~Hz}$ to $14 \mathrm{kHz}$ did not have a negative impact on chondrocytes in vitro. In contrast, the reduction of osteopontin protein, the down- 


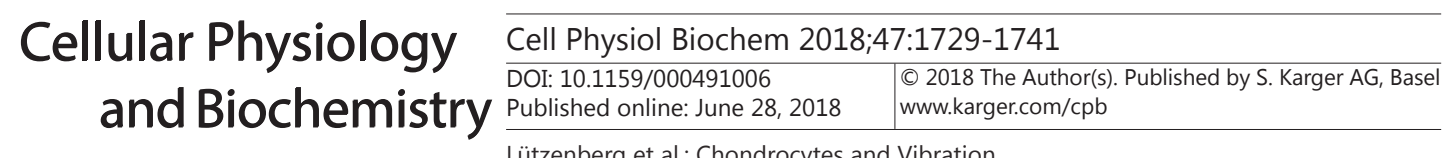

Lützenberg et al.: Chondrocytes and Vibration

regulation of PSMD4 and TBX15 reveal that long-term vibration even positively influences chondrocytes in vitro.

\section{Acknowledgements}

The authors would like to thank the European Space Agency (ESA; (DG, RH) ESA-CORAGBF-Project 2014-03 with acronym: Vibrated Chondrocytes), the German Space Agency (DLR; (DG) BMWi project 50WB1524), and Aarhus University, Denmark for funding. The funders had no role in study design, data collection and analysis, decision to publish, or preparation of the manuscript. We also like to thank Roland Hartig and the section "Multidimensional Microscopy and Cellular Diagnostics" for assistance during microscopy.

D.G., R.L., R.H. and M.W. designed the experiments. C.B., S.R., S.K., K.So. and J.S. executed the experiments and collected the material. J.S. and S.K. performed western blot analyses. K.So. and C.B. performed qPCR analyses. K.Sa., N.H. and H.S. performed the gene array and analysis. M.K. and S.R. performed the staining. J.B. performed the pathway analyses. D.G., and M.W. wrote the manuscript. M.I. and R.H. contributed reagents, materials and analysis tools. All authors reviewed the manuscript.

\section{Disclosure Statement}

The authors declare no competing financial interests.

\section{References}

-1 Poole AR, Kojima T, Yasuda T, Mwale F, Kobayashi M, Laverty S: Composition and structure of articular cartilage: a template for tissue repair. Clin Orthop Relat Res 2001:S26-33.

-2 Wiberg C, Klatt AR, Wagener R, Paulsson M, Bateman JF, Heinegard D, Morgelin M: Complexes of matrilin-1 and biglycan or decorin connect collagen VI microfibrils to both collagen II and aggrecan. J Biol Chem 2003;278:37698-37704.

3 Niu H-J, Wang Q Wang Y-X, Li A, Sun L-W, Yan Y, Fan F, Li D-Y, Fan Y-B: The study on the mechanical characteristics of articular cartilage in simulated microgravity. Acta Mech Sin 2012;28:1488-1493.

4 McCann MR, Yeung C, Pest MA, Ratneswaran A, Pollmann SI, Holdsworth DW, Beier F, Dixon SJ, Seguin CA: Whole-body vibration of mice induces articular cartilage degeneration with minimal changes in subchondral bone. Osteoarthr Cartil 2017;25:770-778.

5 Junbo W, Sijia L, Hongying C, Lei L, Pu W: Effect of low-magnitude different-frequency whole-body vibration on subchondral trabecular bone microarchitecture, cartilage degradation, bone/cartilage turnover, and joint pain in rabbits with knee osteoarthritis. BMC Musculoskelet Disord 2017;18:260.

6 Kaupp JA, Waldman SD: Mechanical vibrations increase the proliferation of articular chondrocytes in highdensity culture. Proc Inst Mech Eng H 2008;222:695-703.

7 Grimm D, Grosse J, Wehland M, Mann V, Reseland JE, Sundaresan A, Corydon TJ: The impact of microgravity on bone in humans. Bone 2016;87:44-56.

8 Fitzgerald J: Cartilage breakdown in microgravity-a problem for long-term spaceflight? NPJ Regen Med 2017;2:10.

9 Wehland M, Aleshcheva G, Schulz H, Saar K, Hubner N, Hemmersbach R, Braun M, Ma X, Frett T, Warnke E, Riwaldt S, Pietsch J, Corydon TJ, Infanger M, Grimm D: Differential gene expression of human chondrocytes cultured under short-term altered gravity conditions during parabolic flight maneuvers. Cell Commun Signal 2015;13:18.

10 Aleshcheva G, Wehland M, Sahana J, Bauer J, Corydon TJ, Hemmersbach R, Frett T, Egli M, Infanger M, Grosse J, Grimm D: Moderate alterations of the cytoskeleton in human chondrocytes after short-term microgravity produced by parabolic flight maneuvers could be prevented by up-regulation of BMP-2 and SOX-9. Faseb J 2015;29:2303-2314.

11 Ulbrich C, Pietsch J, Grosse J, Wehland M, Schulz H, Saar K, Hubner N, Hauslage J, Hemmersbach R, Braun M, van Loon J, Vagt N, Egli M, Richter P, Einspanier R, Sharbati S, Baltz T, Infanger M, Ma X, Grimm D: Differential gene regulation under altered gravity conditions in follicular thyroid cancer cells: relationship between the extracellular matrix and the cytoskeleton. Cell Physiol Biochem 2011;28:185-198. 


\section{Cellular Physiology Cell Physiol Biochem 2018;47:1729-1741 \begin{tabular}{l|l} 
DOI: 10.1159/000491006 & $\begin{array}{l}\text { O 2018 The Author(s). Published by S. Karger AG, Basel } \\
\text { www.karger.com/cpb }\end{array}$
\end{tabular}}

12 Grosse J, Wehland M, Pietsch J, Ma X, Ulbrich C, Schulz H, Saar K, Hubner N, Hauslage J, Hemmersbach R, Braun M, van Loon J, Vagt N, Infanger M, Eilles C, Egli M, Richter P, Baltz T, Einspanier R, Sharbati S, Grimm D: Short-term weightlessness produced by parabolic flight maneuvers altered gene expression patterns in human endothelial cells. FASEB J 2012;26:639-655.

13 Kopp S, Slumstrup L, Corydon TJ, Sahana J, Aleshcheva G, Islam T, Magnusson NE, Wehland M, Bauer J, Infanger M, Grimm D: Identifications of novel mechanisms in breast cancer cells involving ductlike multicellular spheroid formation after exposure to the Random Positioning Machine. Sci Rep 2016;6:26887.

14 Infanger M, Shakibaei M, Kossmehl P, Hollenberg SM, Grosse J, Faramarzi S, Schulze-Tanzil G, Paul M, Grimm D: Intraluminal application of vascular endothelial growth factor enhances healing of microvascular anastomosis in a rat model. J Vasc Res 2005;42:202-213.

15 Infanger M, Grosse J, Westphal K, Leder A, Ulbrich C, Paul M, Grimm D: Vascular endothelial growth factor induces extracellular matrix proteins and osteopontin in the umbilical artery. Ann Vasc Surg 2008;22:273284.

16 Warnke E, Pietsch J, Kopp S, Bauer J, Sahana J, Wehland M, Krüger M, Hemmersbach R, Infanger M, Lutzenberg R, Grimm D: Cytokine Release and Focal Adhesion Proteins in Normal Thyroid Cells Cultured on the Random Positioning Machine. Cell Physiol Biochem 2017;43:257-270.

17 Riwaldt S, Monici M, Graver Petersen A, Birk Jensen U, Evert K, Pantalone D, Utpatel K, Evert M, Wehland M, Krüger M, Kopp S, Frandsen S, Corydon T: Preparation of A Spaceflight: Apoptosis Search in Sutured Wound Healing Models. Int J Mol Sci 2017; 18:2604.

18 Benjamini Y, Hochberg Y: Controlling the False Discovery Rate: A Practical and Powerful Approach to Multiple Testing. J R Stat Soc Series B Stat Methodol 1995;57:289-300.

19 Riwaldt S, Bauer J, Wehland M, Slumstrup L, Kopp S, Warnke E, Dittrich A, Magnusson NE, Pietsch J, Corydon TJ, Infanger M, Grimm D: Pathways Regulating Spheroid Formation of Human Follicular Thyroid Cancer Cells under Simulated Microgravity Conditions: A Genetic Approach. Int J Mol Sci 2016;17:528.

-20 Bauer J, Kopp S, Schlagberger EM, Grosse J, Sahana J, Riwaldt S, Wehland M, Luetzenberg R, Infanger M, Grimm D: Proteome Analysis of Human Follicular Thyroid Cancer Cells Exposed to the Random Positioning Machine. Int J Mol Sci 2017;18:546.

21 Szklarczyk D, Morris JH, Cook H, Kuhn M, Wyder S, Simonovic M, Santos A, Doncheva NT, Roth A, Bork P, Jensen LJ, von Mering C: The STRING database in 2017: quality-controlled protein-protein association networks, made broadly accessible. Nucleic Acids Res 2017;45: D362-D368 .

22 Shi JX, Li JS, Hu R, Li XM, Wang H: CAF1-knockout mice are more susceptive to lipopolysaccharide-induced acute lung injury. J Inflamm Res 2016;9:115-121.

23 Shi JX, Li JS, Hu R, Shi Y, Su X, Li Q, Zhang F: CNOT7/hCAF1 is involved in ICAM-1 and IL-8 regulation by tristetraprolin. Cell Signal 2014;26:2390-2396.

24 Ahmed M, Kundu GC: Osteopontin selectively regulates p70S6K/mTOR phosphorylation leading to NFkappaB dependent AP-1-mediated ICAM-1 expression in breast cancer cells. Mol Cancer 2010;9:101.

25 Dong Q, Zhu X, Dai C, Zhang X, Gao X, Wei J, Sheng Y, Zheng Y, Yu J, Xie L, Qin Y, Qiao P, Zhou C, Yu X, Jia H, Ren N, Zhou H, Ye Q, Qin L: Osteopontin promotes epithelial-mesenchymal transition of hepatocellular carcinoma through regulating vimentin. Oncotarget 2016;7:12997-13012.

26 Che X, Chi F, Wang L, Jong TD, Wu CH, Wang X, Huang SH: Involvement of IbeA in meningitic Escherichia coli K1-induced polymorphonuclear leukocyte transmigration across brain endothelial cells. Brain Pathol 2011;21:389-404.

27 Wang JB, Liu SJ, Chen HY, Wang P: Effects of low-magnitude whole body vibration (WBV) on knee osteoarthritis in rabbits. Sichuan Da Xue Xue Bao Yi Xue Ban 2017;48:537-542.

28 Ito Y, Kimura T, Nam K, Katoh A, Masuzawa T, Kishida A: Effects of vibration on differentiation of cultured PC12 cells. Biotechnol Bioeng 2011;108:592-599.

29 Pamon T, Bhandal V, Adler BJ, Ete Chan M, Rubin CT: Low-intensity vibration increases cartilage thickness in obese mice. J Orthop Res 2018;36:751-759.

-30 O'Conor CJ, Case N, Guilak F: Mechanical regulation of chondrogenesis. Stem Cell Res Ther 2013;4:61.

31 Montagne K, Onuma Y, Ito Y, Aiki Y, Furukawa KS, Ushida T: High hydrostatic pressure induces proosteoarthritic changes in cartilage precursor cells: A transcriptome analysis. PLoS One 2017;12:e0183226. 


\section{Cellular Physiology Cell Physiol Biochem 2018;47:1729-1741 \begin{tabular}{ll|l} 
DOI: 10.1159/000491006 & and Biochemistry 2018 The Author(s). Published by S. Karger AG, Basel \\
Published online: June 28, 2018 & $\begin{array}{l}\text { www.karger.com/cpb } \\
\text { and }\end{array}$
\end{tabular}}

32 De Palma A, Cheleschi S, Pascarelli NA, Giannotti S, Galeazzi M, Fioravanti A: Hydrostatic pressure as epigenetic modulator in chondrocyte cultures: A study on miRNA-155, miRNA-181a and miRNA-223 expression levels. J Biomech 2018;66:165-169.

33 Lane Smith R, Trindade MC, Ikenoue T, Mohtai M, Das P, Carter DR, Goodman SB, Schurman DJ: Effects of shear stress on articular chondrocyte metabolism. Biorheology 2000;37:95-107.

-34 Smith RL, Carter DR, Schurman DJ: Pressure and shear differentially alter human articular chondrocyte metabolism: a review. Clin Orthop Relat Res 2004:427:S89-95.

-35 Maldonado M, Nam J: The role of changes in extracellular matrix of cartilage in the presence of inflammation on the pathology of osteoarthritis. Biomed Res Int 2013;2013:284873.

36 Akimoto T, Kawanishi M, Ushida T: Mechanical stress and tissue engineering. Clin Calcium 2008;18:13131320.

37 Yeh TC, Ogawa W, Danielsen AG, Roth RA: Characterization and cloning of a 58/53-kDa substrate of the insulin receptor tyrosine kinase. J Biol Chem 1996;271:2921-2928.

-38 Takenawa T, Miki H: WASP and WAVE family proteins: key molecules for rapid rearrangement of cortical actin filaments and cell movement. J Cell Sci 2001;114:1801-1809.

-39 Corydon TJ, Kopp S, Wehland M, Braun M, Schütte A, Mayer T, Hulsing T, Oltmann H, Schmitz B, Hemmersbach R, Grimm D: Alterations of the cytoskeleton in human cells in space proved by life-cell imaging. Sci Rep 2016;6:20043.

-40 Sun W, Zhao R, Yang Y, Wang H, Shao Y, Kong X: Comparative study of human aortic and mitral valve interstitial cell gene expression and cellular function. Genomics 2013;101:326-335.

41 Karin M, Delhase M: The I kappa B kinase (IKK) and NF-kappa B: key elements of proinflammatory signalling. Semin Immunol 2000;12:85-98.

-42 Li Y, Jiang W, Wang H, Deng Z, Zeng C, Tu M, Li L, Xiao W, Gao S, Luo W, Lei G: Osteopontin Promotes Expression of Matrix Metalloproteinase 13 through NF-kappaB Signaling in Osteoarthritis. Biomed Res Int 2016;2016:6345656.

43 Gravallese EM: Osteopontin: a bridge between bone and the immune system. J Clin Invest 2003;112:147149.

44 Denhardt DT, Noda M: Osteopontin expression and function: Role in bone remodeling. J Cell Biochem 1998;72 Suppl 30-31:92-102.

45 Zhang FJ, Gao SG, Cheng L, Tian J, Xu WS, Luo W, Song Y, Yang Y, Lei GH: The effect of hyaluronic acid on osteopontin and CD44 mRNA of fibroblast-like synoviocytes in patients with osteoarthritis of the knee. Rheumatol Int 2013;33:79-83.

46 Pullig O, Weseloh G, Gauer S, Swoboda B: Osteopontin is expressed by adult human osteoarthritic chondrocytes: protein and mRNA analysis of normal and osteoarthritic cartilage. Matrix Biol 2000;19:245255.

47 Gao SG, Li KH, Zeng KB, Tu M, Xu M, Lei GH: Elevated osteopontin level of synovial fluid and articular cartilage is associated with disease severity in knee osteoarthritis patients. Osteoarthritis Cartilage 2010;18:82-87.

48 Gao SG, Yu Y, Zeng C, Lu ST, Tian J, Cheng C, Li LJ, Lei GH: Phosphorylation of osteopontin has proapoptotic and proinflammatory effects on human knee osteoarthritis chondrocytes. Exp Ther Med 2016;12:34883494 .

49 Benjamin M, Archer CW, Ralphs JR: Cytoskeleton of cartilage cells. Microsc Res Tech 1994;28:372-377.

-50 Herrmann H, Bar H, Kreplak L, Strelkov SV, Aebi U: Intermediate filaments: from cell architecture to nanomechanics. Nat Rev Mol Cell Biol 2007;8:562-573.

51 Goldman RD, Khuon S, Chou YH, Opal P, Steinert PM: The function of intermediate filaments in cell shape and cytoskeletal integrity. J Cell Biol 1996;134:971-983.

52 Aleshcheva G, Sahana J, Ma X, Hauslage J, Hemmersbach R, Egli M, Infanger M, Bauer J, Grimm D: Changes in morphology, gene expression and protein content in chondrocytes cultured on a random positioning machine. PLoS One 2013;8:e79057.

53 Ma X, Wehland M, Aleshcheva G, Hauslage J, Wasser K, Hemmersbach R, Infanger M, Bauer J, Grimm D: Interleukin-6 expression under gravitational stress due to vibration and hypergravity in follicular thyroid cancer cells. PLoS One 2013;8:e68140. 